\title{
Simultaneous Determination of Dihydroxybenzene Isomers by MWCNTs-NTiO 2 Modified Glassy Carbon Electrode
}

\author{
Chun Wei ${ }^{1}$, Yuyan Zhao ${ }^{2}$, Jichuan Huo ${ }^{3}$, Qiuxia Yang ${ }^{2}$, Chengyao $\mathrm{Hu}^{1}$, Ying Zhang, ${ }^{2, *}$ \\ ${ }^{1}$ School of Materials Science and Engineering, Southwest University of Science and Technology, \\ Mianyang 621010, P. R. China \\ ${ }^{2}$ School of Chemistry and Chemical Engineering, University of Jinan, Jinan 250022, P. R. China \\ ${ }^{3}$ Analytical and Testing Center, Southwest University of Science and Technology, Mianyang 621010, \\ P. R. China \\ *E-mail: chm_zhangy@ujn.edu.cn
}

doi: $10.20964 / 2017.02 .54$

Received: 2 November 2016 / Accepted: 26 December 2016 / Published: 30 December 2016

\begin{abstract}
In this paper, multi-wall carbon nanotubes and nano-titanium dioxide $\left(\mathrm{MWCNTs}-\mathrm{NTiO}_{2}\right)$ modified electrode is easily prepared by one-step coating. The nano- $\mathrm{TiO}_{2}$ collid is prepared by sol-gel method at room temperature to improve the dispersion and electrical conductivity of original MWCNTs on glass carbon electrode (GCE). The electrochemical behaviors of dihydroxybenzene isomers are investigated

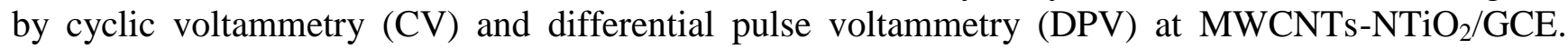
Hydroquinone (HQ), catechol (CC) and resorcinol (RC) all exhibit sensitive responses at original MWCNTs modified electrode. However, the peak currents of $\mathrm{HQ}, \mathrm{CC}$ and RC present much enhanced signals at MWCNTs-NTiO ${ }_{2}$ modified electrode, proving a good synergetic effect of $\mathrm{NTiO}_{2}$ and MWCNTs. The individual and simultaneous determination of HQ, CC and RC at MWCNTs$\mathrm{NTiO}_{2} / \mathrm{GCE}$ are studied, and obtains good liner relations in a wide range. The limits of detection for $\mathrm{HQ}, \mathrm{CC}$ and RC are $93 \mathrm{nmol} \mathrm{L}-1,210 \mathrm{nmol} \mathrm{L}^{-1}$ and $32 \mathrm{nmol} \mathrm{L}^{-1}(\mathrm{~S} / \mathrm{N}=3)$, respectively. This kind of sensor has been applied for simultaneous determination of HQ, CC and RC in artificial wastewater and obtained good results.
\end{abstract}

Keywords: dihydroxybenzene; eletrochemical sensor; MWCNTs; $\mathrm{NTiO}_{2}$; isomer

\section{FULL TEXT}

(C) 2017 The Authors. Published by ESG (www.electrochemsci.org). This article is an open access article distributed under the terms and conditions of the Creative Commons Attribution license (http://creativecommons.org/licenses/by/4.0/). 